\title{
ОБЕСПЕЧЕНИЕ КОМПАНИИ КВАЛИФИЦИРОВАННЫМ ПЕРСОНАЛОМ ПУТЕМ ОРГАНИЗАЦИИ ДУАЛЬНОГО ОБРАЗОВАНИЯ НА ОСНОВЕ ПРОЦЕССНОГО ПОДХОДА
}

\author{
(c) 2020 Смирнов Алексей Андреевич \\ аспирант кафедры менеджмента и предпринимательства \\ Уральский государственный экономический университет, Россия, Екатеринбург \\ E-mail: a.a.smirnov22@mail.ru
}

Статья описывает организацию дуального образования в крупной российской металлургической компании на основе процессного подхода. Автором представлена процессная модель подготовки рабочих кадров и ключевые показатели эффективности процесса, выявлена проблема неучастия в процессе профсоюза.

Ключевые слова: обеспечение персоналом, подготовка рабочих кадров, дуальное обучение, управление персоналом, процессный подход, обучение персонала, металлургическая компания, процессная модель.

Дефицит квалифицированных кадров в настоящее время является одним из основных барьеров роста эффективности деятельности производственных компаний. Стройная система профессиональной подготовки, существовавшая в СССР и успешно обеспечивавшая организации инженерно-техническим и рабочим персоналом, была сломана, поскольку держалась на государственных заказах на подготовку в ситуации наличия одного собственника. В условиях рыночных отношений, появления частной собственности, государство не могло дать точный прогноз потребности экономики в специалистах различных профилей, а новоявленные работодатели не хотели тратить деньги на подготовку будущих работников, не понимали, что обучение - это долгосрочные инвестиции в человеческие ресурсы [8], это привело к закрытию ряда организаций среднего профессионального и большинства - начального профессионального образования. К началу 2000-х крупные компании активно развернули программы профессиональной подготовки своих имеющихся и будущих работников [14], поскольку это был единственно возможный путь обеспечить свою фирму кадрами нужной квалификации [7].

Для организации подготовки кадров для крупной компании необходимо ее тесное сотрудничество с образовательными структурами, что наилучшим образом реализуется в системе дуального образования, под которой понимают такую организацию образовательного процесса, когда практическая часть подготовки проходит на рабочем месте, а теоретическая часть - на базе образовательной организации [4, с.357]. Си- стема, которую в последствии назвали дуальной, зародилась в Германии в середине 1960-х гг. [3], где она организована таким образом, что 1-2 дня в неделю учащиеся проходят обучение в учебном заведении, остальное учебное время приобретают практические навыки на рабочем месте [5]. Такой способ обучения доказал свою эффективность не только в европейских странах [2], например, в Нидерландах [11], но и в Китае [9], Турции [12], Казахстане [14] и других странах мира.

В России дуальная система обучения начала активно применяться с 2014 года, когда под руководством Агентства Стратегических Инициатив стартовал пилотный проект по применению дуального образования в нескольких субъектах Российской Федерации. Результаты внедрения проекта в субъектах отличаются значительно: так, по данным рейтинга мониторинга качества подготовки кадров, только четыре региона распространили эту практику более чем на половину профессиональных образовательных организаций [10].

Свердловская область также была включена в данный пилотный проект, однако по итогам 2019 год субъект замыкает рейтинг эффективности внедрения системы: доля организаций, реализовавших элементы дуального обучения, составила лишь 7,1\%, в то время как в Белгородской области $-85,7 \%$, Нижегородской $-63,0 \%$.

Целью данной статьи является анализ положительного опыта внедрения элементов дуального образования для эффективного обеспечения квалифицированным персоналом группы компаний ЧТПЗ (российская металлургическая 
группа) - одного из крупнейших производителей трубной продукции.

Система дуального образования в компании формируется и развивается на основе принципов качества и социальной ответственности, направленных на выявление и удовлетворение требований и ожиданий потребителей и заинтересованных сторон корпоративной образовательной программы по подготовке персонала по профессиям и специальностям «Будущее Белой металлургии». При осуществлении подготовки кадров в компании применяются системный и процессный подходы, направленные на постоянное улучшение системы и достижение запланированных результатов.

В качестве элементов системы дуального образования в Группе компаний ЧТПЗ считаются, во-первых, участники системы дуального обра- зования и, во-вторых, стейкхолдеры (заинтересованные стороны). Участниками образовательного процесса называются:

- структурные подразделения компании, участвующие в реализации программы «Будущее Белой металлургии»;

- учебные центры, образовательные организации, и другие внешние организации, заключившие договор о сетевой реализации программ;

- абитуриенты студенты выпускники, преподавателей, кураторов, мастеров производственного обучения), наставники и другие группы и индивидуумы, которые принимают участие в образовательном процессе;

- консультативные и коллегиальные органы управления образовательным процессом.

К заинтересованным сторонам системы ду-

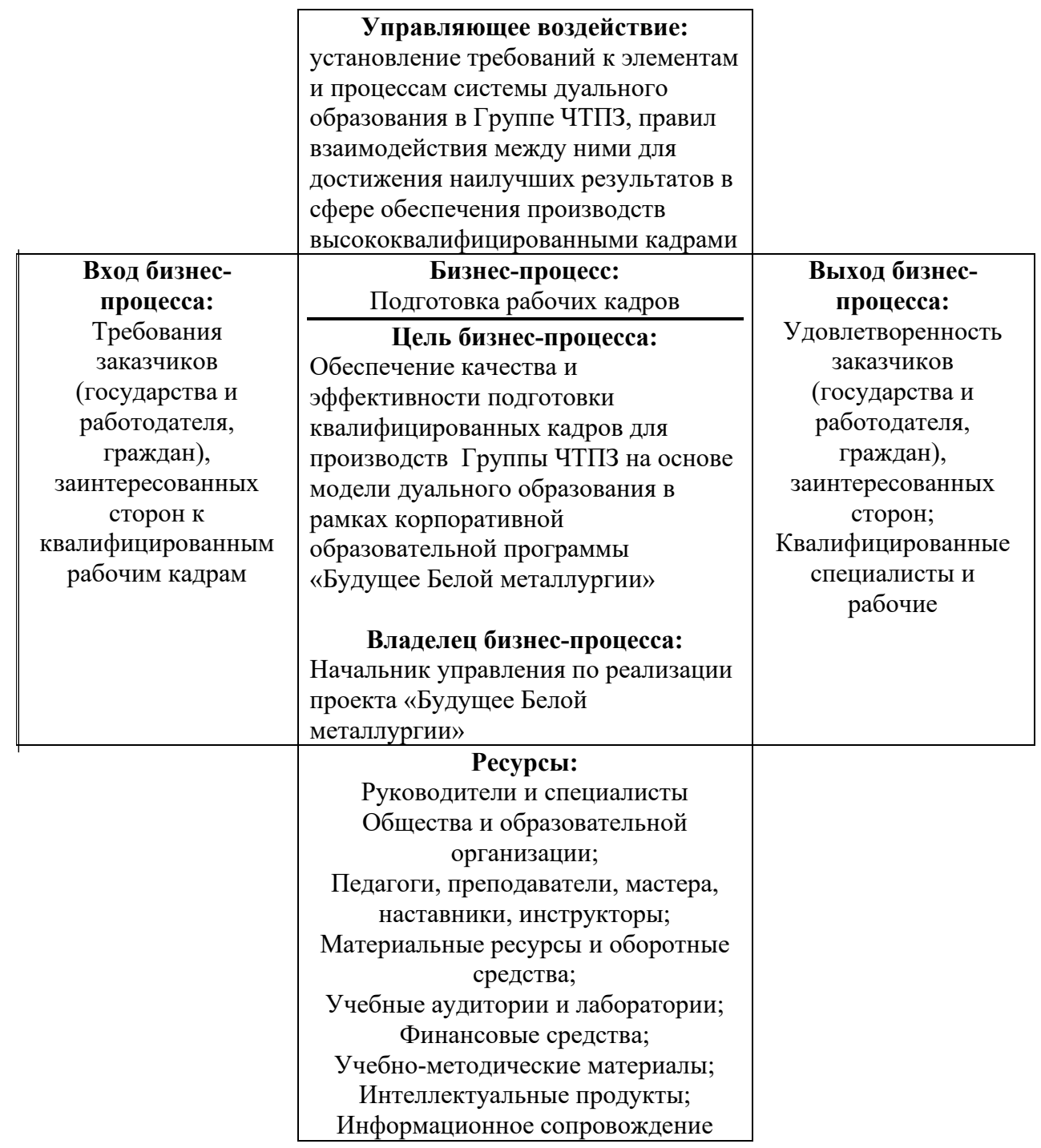

Рисунок 1. Процессная модель подготовки рабочих кадров на основе системы дуального образования в Группе ЧТПЗ 
ального образования относятся: руководство и акционеры компании, органы власти и местного самоуправления, отраслевые союзы и ассоциации, общественные и некоммерческие организации, профсоюзы, население городов присутствия Группы ЧТПЗ, семьи абитуриентов, студентов и выпускников программы.

В современной науке и практике менеджмента процессный подход основывается на системном управлении, представляет компанию в качестве единого организма, в котором различные бизнес-процессы протекают; на входе процесса ресурсы принимаются для дальнейшей модификации, на выходе получается требуемый продукт, результат или услуга. Конечной целью подбора и подготовки кадров в Группе ЧТПЗ выступает обеспечение компании квалифицированным персоналом, отвечающим требованиям производства, способного работать в условиях высокотехнологичного металлургического производства, разделяющего философию Белой металлургии, под которой понимается философия преображения личности, рабочей среды, производственного пространства и социума. На рисунке 1 представлена процессная модель подготовки рабочих кадров на основе системы дуального образования в Группе ЧТПЗ.

Выпускники программы «Будущее Белой Металлургии» должны успешно пройти государственную итоговую аттестацию в СПО, включая демонстрационный экзамен в соответствии с «WorldSkills», успешно сдать квалификационные экзамены или пройти оценку на соответствие профессиональным стандартам. В компании принята модель компетенций, состоящая из нескольких уровней, выпускник программы должен соответствовать не менее, чем второму уровню этой модели. Далее для всех выпускников строятся карьерограммы (карьерные карты), с которыми выпускников программы знакомят еще в процессе обучения. Это позволяет удерживать квалифицированный персонал.

В соответствии с современным подходом к управлению системой профессионального обучения персонала [6] и принятому в Группе чТПЗ стандарту управления системой дуального обра-

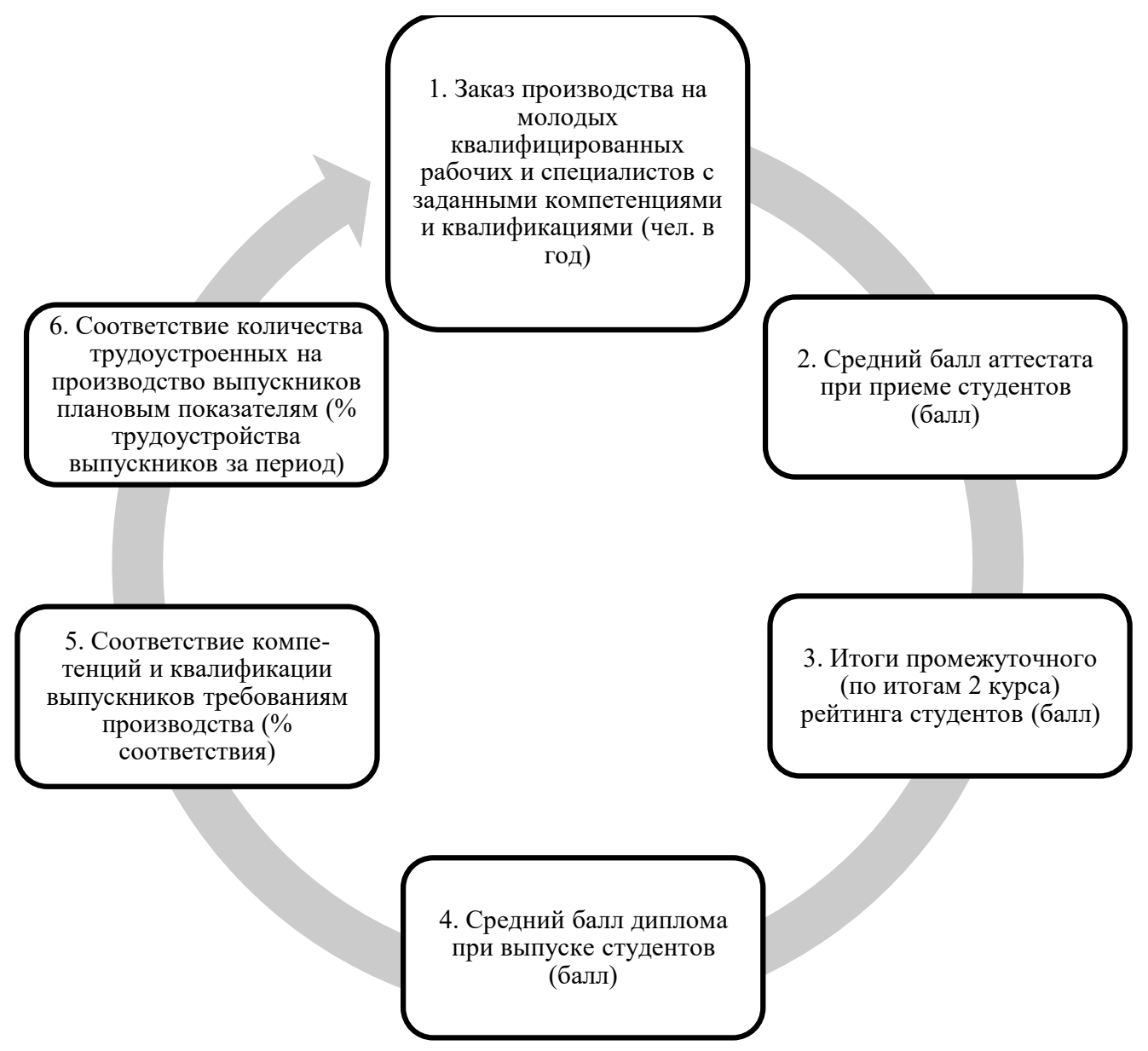

Рисунок 2. Ключевые показатели результативности системы дуального образования в Группе чТПЗ 
зования, для процесса «подготовка рабочих кадров» в компании разработана методика оценки его результативности по этапам процесса. В результате получают информацию, которая используется для разработки корректирующих и предупреждающих действий, предложений по совершенствованию процессов.

Система ключевых показателей результативности системы дуального образования включает шесть показателей, отслеживаемых ежемесячно (рисунок 2).

Результаты оценки, проводимой в режиме мониторинга, позволяют определить результативность программы по итогам учебного года и учитываются при формировании заработной платы руководителей системы.

Таким образом, описанный процессный подход позволил компании не испытывать острого дефицита кадров и готовить рабочий персонал, обладающий нужными компетенциями [1] не только в текущем периоде, но и в ближайшей перспективе.

Вместе с тем, внедрение системы дуального образования в России требует согласованной работы компаний, особенно крупных, оснащенных современным оборудованием и использующих прогрессивные технологии, государства и образовательных учреждений начального и среднего профессионального образования. Важную роль в развитии дуальной системы подготовки высококвалифицированных кадров в соответствии с требованиями рынка труда должны играть профсоюзы, которые в настоящее время в такие программы не вовлечены. Хотя профсоюзы заявлены в качестве заинтересованных сторон, им не установлены какие-либо требования, ключевые показатели, функции. Дуальное образование является важнейшим способом обеспечения компаний квалифицированным персоналом.

\section{Библиографический список}

1. Быкова Е.О., Чистякова В.В. Дуальная система профессионального образования как условие успешной реализации компетентностного подхода в современном образовании // Источник. 2016. № 2. С. 16-17.

2. Гребенникова В.М., Гребенников О.В. Дуальное образование: мировая практика и современные российские реалии // Образование и общество. 2020. № 3 (122). С. 12-17.

3. Дыканалиев К.М., Бакиров Б.Ж., Асаналиев М.К. Реализация технологии дуального обучения в образовательном учреждении среднего профессионального образования // Образование и наука в современных условиях. 2017. № 1 (10). С. 106-109.

4. Каплун М. Ю. Подготовка кадров для современного машиностроительного комплекса на основе системы дуального образования // Химия. Экология. Урбанистика. 2020. Т. 2020-1. С. 356-360.

5. Козлова Л.П., Козлова О.А. Применение дуальной системы образования // Планирование и обеспечение подготовки кадров для промышленно-экономического комплекса региона. 2016. Т. 1. С. 191-194.

6. Кулькова И.А. Критерии оценки эффективности управления системой внутрифирменного обучения // В книге: Современные управленческие технологии: от теории и методологии к практическим решениям. Монография. Под научной редакцией И.Н. Ткаченко. Екатеринбург, 2016. С. 116-137.

7. улькова И.А., ГусакД.Г. Кадровый дефицит: мифы и реальность // Управленец. 2012. № 5-6 (33-34). С. $22-25$.

8. Курячая Е. А. Организационное обучение - метод долгосрочных инвестиций в человеческие ресурсы при модификации традиционной иерархической организационной структуры управления в самообучающуюся организацию // Human Progress, 2018, Том 4, № 1. С. 4.

9. Лю Ч. О развитии дуального образования в профессиональном образовании Китая // Ученые записки Забайкальского государственного университета. 2016. Т. 11. № 6. С. 74-79.

10. Некрасов С.И., Захарченко Л В., Некрасова Ю.А. Пилотный проект «Дуальное обучение»: критический взгляд специалистов // Профессиональное образование. Столица. 2015. № 4. С. 9-16.

11. Пануева Ю.В.Д уальное образование в Нидерландах как вариант для российских студентов // Экономика и социум. 2016. № 12-3. С. 225-233.

12. Плешакова А.Ю. Проблемы внедрения дуальной системы германии в профессиональное образование Турции // Инновационные проекты и программы в образовании. 2019. № 6 (66). С. 57-62.

13. Yergalieva D.T., Golovin I.L., Komleva Ye.V., Baytuganova M.O. Problems of Dual Education in the Republic of Kazakhstan // Russian Journal of Sociology. 2017. № 3 (1). C. 17-22.

14. Zhalezka B.A., Siniauskaya V.A. Dual education in the sphere of automotive industry // Экономическая наука сегодня. 2020. № 11. С. 151-156. 